\title{
Elevation as a treatment for fasciotomy wound closure
}

\author{
Omar Bengezi MBBS MD FRCSC ${ }^{1}$, Anthony $\mathrm{VO}^{2}$
}

O Bengezi, A Vo. Elevation as a treatment for fasciotomy wound closure. Can J Plast Surg 2013;21(3):192-194.

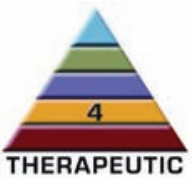

There are currently numerous techniques described in the literature that attempt to optimize wound closure following a fasciotomy. However, primary closure of fasciotomy wounds continues to be difficult to accomplish successfully because of the underlying edema sustained from the compartment syndrome. The approach described in the present report is simple and physiologically sound, and addresses the underlying pathology. The authors focus on alleviating edema by strictly elevating the limb, followed by primary closure. Twelve consecutive fasciotomy wounds, referred from 2005 to 2012, were closed using this approach. The average wound closure time was 3.4 days (range three to five days) following the initial consultation. All 12 fasciotomy wounds responded with no revisions, complications, failures or loss of skin sensation. The approach was successful in all anatomical locations that were closed and conversion to any techniques currently available in the literature was not necessary. There are no costs associated with this approach, making it practical in settings with limited resources. It has a high success rate, superior cosmetic results and, most importantly, it achieves an efficient closure time. Therefore, this approach is superior to current techniques and should be a part of a plastic surgeon's armamentarium.

Key Words: Compartment syndrome; Elevation; Fasciotomy; Wound closure

\section{Lélévation pour traiter la fermeture de la plaie après une fasciotomie}

De nombreuses techniques sont décrites dans les publications pour optimiser la fermeture de la plaie après une fasciotomie. Cependant, il est toujours difficile de fermer ce type de plaie, à cause de l'œdème sous-jacent attribuable au syndrome des loges. La démarche décrite dans le présent rapport a le mérite d'être simple, d'être solide sur le plan physiologique et de régler la pathologie sous-jacente. Les auteurs s'attachent à soulager l'œdème en soulevant rigoureusement le membre, puis à procéder à la fermeture primaire. Douze (12) plaies de fasciotomie consécutives, aiguillées entre 2005 et 2012, ont été fermées grâce à cette approche. Le délai moyen de fermeture des plaies étaient de 3,4 jours (plage de trois à cinq jours) après la consultation initiale. Les 12 plaies de fasciotomie ont répondu sans révisions, complications, échecs ou sensations de perte cutanée. La démarche a fonctionné dans tous les foyers anatomiques fermés, et il n'a pas été nécessaire d'envisager l'une des techniques actuellement proposées dans les publications. Cette démarche ne coûte rien, ce qui est pratique dans les lieux aux ressources limitées. Celle-ci est liée à un taux de succès élevé, à des résultats esthétiques supérieurs et, par-dessus tout, à un délai de fermeture efficace. Par conséquent, cette démarche est supérieure aux techniques actuelles et devrait faire partie de l'arsenal du plasticien.
$\mathrm{C}$

ompartment syndrome is a severe medical condition in which there is an increase in the interstitial pressure within closed and unforgiving osteofascial spaces. This causes compression of vascular structures within these compartments, leading to muscle and nerve ischemia and, ultimately, tissue loss. A fasciotomy is the most effective treatment for a patient with compartment syndrome. However, the fasciotomy wound often presents a problem for surgeons to close primarily due to the persistent tissue edema and skin contracture (1). As such, fasciotomy wounds are often aesthetically unappealing, which can be debilitating for the patients. In a study involving 60 patients who underwent fasciotomy wound closure, Fitzgerald et al (2) reported that $23 \%$ were so upset by the appearance of the wound that they covered it, $28 \%$ changed hobbies and $12 \%$ changed occupation.

Currently, there are numerous techniques that attempt to optimize wound closure following a fasciotomy. Split-thickness skin grafting is the most common method (3). However, it requires an additional operative procedure, prolongs hospital stay, results in an additional wound and complicates wound care at both sites. Furthermore, there is always the possibility of graft failure. The final aesthetic result is a thin, unappealing scar without sensation $(1,4,5)$. Vacuum-assisted closure (VAC) is another approach that had a reported mean wound closure time of 6.7 days in one study (6) and 11 days in another (7). However, the daily cost of VAC is approximately $\$ 174$ (8). In addition, VAC may fail to provide adequate skin edge approximation for final closure and, as a result, an additional closing technique would be required (9).

In the literature, there is a plethora of innovative techniques focusing on dermal apposition, including the vessel loop shoelace (10), subcuticular suture (11), Ty-Rap (Thomas \& Betts, USA) (9), Sure-Closure
(Life Medical Sciences Inc, USA) (1), Dynamic Wound Closure (Canica Design Inc, Canada) (12), STAR (WoundTEK Inc, USA) (1) and Silver Bullet Wound Closure Device (Boehringer Laboratories, USA) (13). The shoelace technique achieves closure in a mean of 8.8 days (range six to 19 days) (10). The subcuticular suture technique causes inflammation around sutures (14) that often break and require replacement (11). Both of these techniques focus solely on dermal apposition, but they do not manage the underlying edema. As a result, fasciotomy wounds can be closed with edema present causing excessive tension. This can result in skin necrosis and recurrent compartment syndromes (12).

Commercial devices such as the Sure-Closure, STAR and the Silver Bullet Wound Closure device are often expensive. For example, the Sure Closure device costs in the range of $\$ 300$ to $\$ 500$ (12), and the cost for one Silver Bullet Wound Closure device is USD\$575 in (13). Therefore, countries or hospitals with limited resources have difficulty in obtaining these devices.

The pitfall with all dermal apposition techniques is that they cannot be applied until the edema settles from the compartment syndrome, which often requires three to five days postoperatively. With these devices in place, they are labour intensive and time consuming because the surgeon is required to tighten them daily. When these devices are applied with the edema present, the tension created by the combination of the two can cause skin necrosis and recurrence of compartment syndrome. Therefore, close monitoring of the limb during closure is often required (15).

Many studies have shown that primary closure of fasciotomy wounds is often impossible secondary to persistent tissue edema $(1,3,12)$. The edema from the compartment syndrome causes wound 


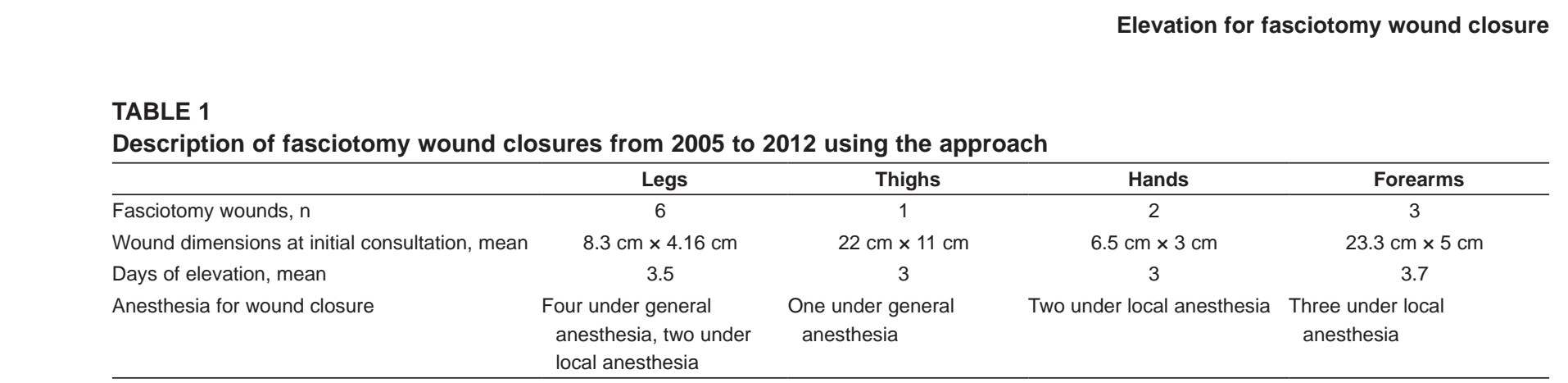

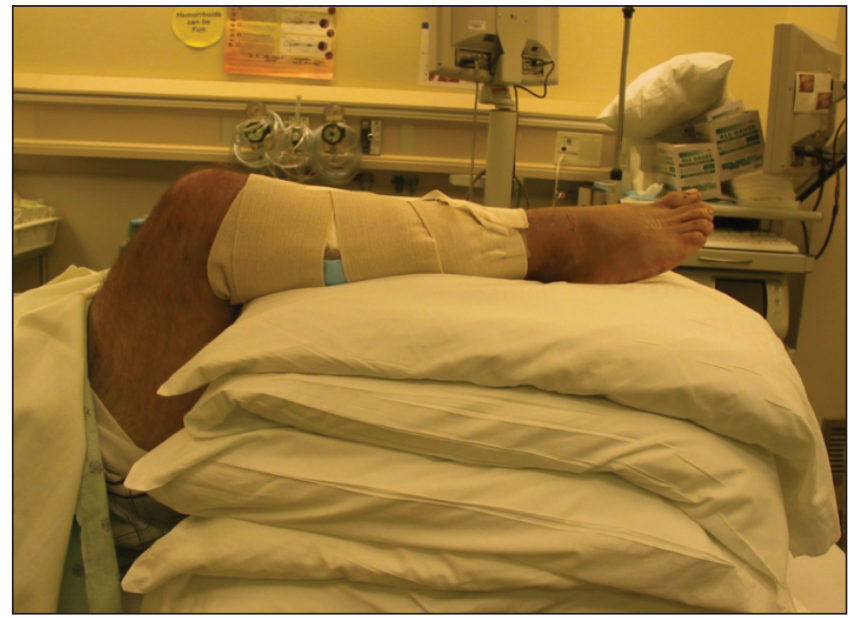

Figure 1) Elevation of the limb on a minimum of five pillows is required for fasciotomy wound closure success

tension and complications when primary closure is attempted. We agree that the edema is the underlying problem for the encountered difficulty in closing fasciotomy wounds. Therefore, our approach focuses on alleviating the edema sustained from the compartment syndrome. Once we overcome the edema, we reduce the tissue swelling and solve the problem encountered during primary closure. Our approach is based on a simple observation that elevation decreases edema. With that in mind, we achieve primary closure of fasciotomy wounds following elevation of the limb with strict guidelines. Compared with current techniques, it does not require a device, has zero cost, is easy to implement, has fewer complications and minimizes patient management. This means that our approach is applicable in countries and hospitals with limited resources.

\section{METHODS}

All patients underwent fasciotomies performed by orthopedic surgeons and were solely referred to the authors for wound closure. Twelve consecutive fasciotomy wounds (six lower legs, one thigh, two hands and three forearms) in eight patients, with a mean age of 35 years (range 16 to 70 years), were closed from 2005 to 2012 (Table 1). The approach was explained to all patients and they were made aware of the potential complications.

\section{The approach}

The approach was explained to all patients with emphasis placed on the importance of limb elevation. All patients were informed repeatedly that lowering their fasciotomy wound for a few minutes could disrupt hours of elevation treatment. Elevation was rigorously enforced at all times. If patients believed that they might forget this, their limb was elevated on an intravenous pole. Following the initial consultation with the plastic surgeon, the limb was immediately elevated on pillows. A minimum of five pillows was required to ensure success (Figure 1). Patients were allowed to lower the limb only to use the restroom. Wound dressings were changed daily and tensor bandages were applied from the distal to the proximal end to help alleviate the edema. The surgeon first examined the wound on the third day from the initial

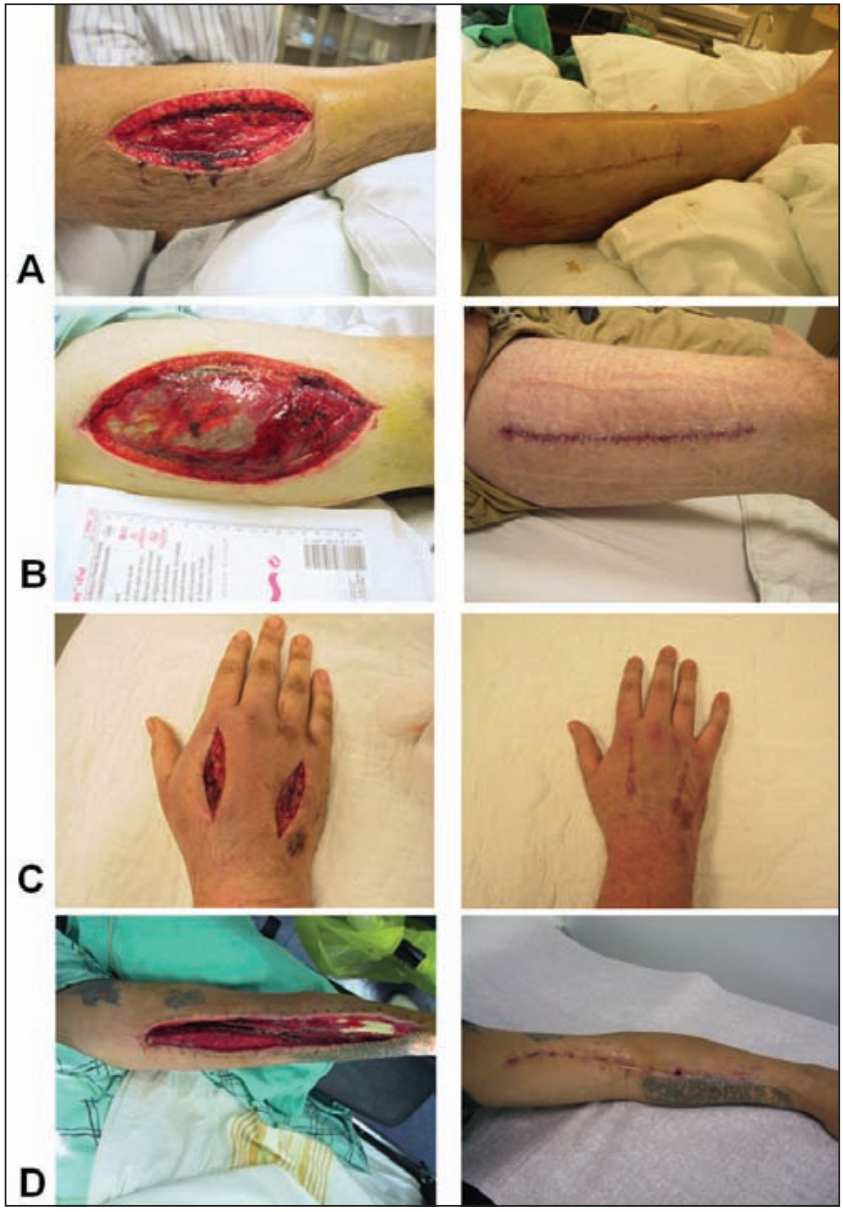

Figure 2) Fasciotomy wound closed following elevation. Fasciotomy wound closure before and after in leg (A), thigh (B), hand (C) and forearm (D)

consultation and daily thereafter. Skin pinching was performed to determine skin laxity around the wound to safely allow for primary closure. Once skin laxity was deemed to be safe for closure, the patient was taken to the operating room to have their wound debrided, undermined and closed primarily without tension.

\section{RESULTS}

All 12 consecutive fasciotomy wound closures were successful following elevation with strict guidelines. There were no revisions, complications, failures, loss of skin sensation or conversion to any other currently available techniques. Our approach was successful in all anatomical locations closed (lower legs, thighs, forearms and upper arms) (Figure 2). It was also successful in closing multiple fasciotomy wounds on the same limb. In one patient, four fasciotomy wounds were closed simultaneously strictly using elevation (Figure 3). All fasciotomy wounds were closed in a mean of 3.4 days (range three to five days) after the initial consultation. Following closure, patients were followed for a mean of 4.2 months (range two to eight months). 

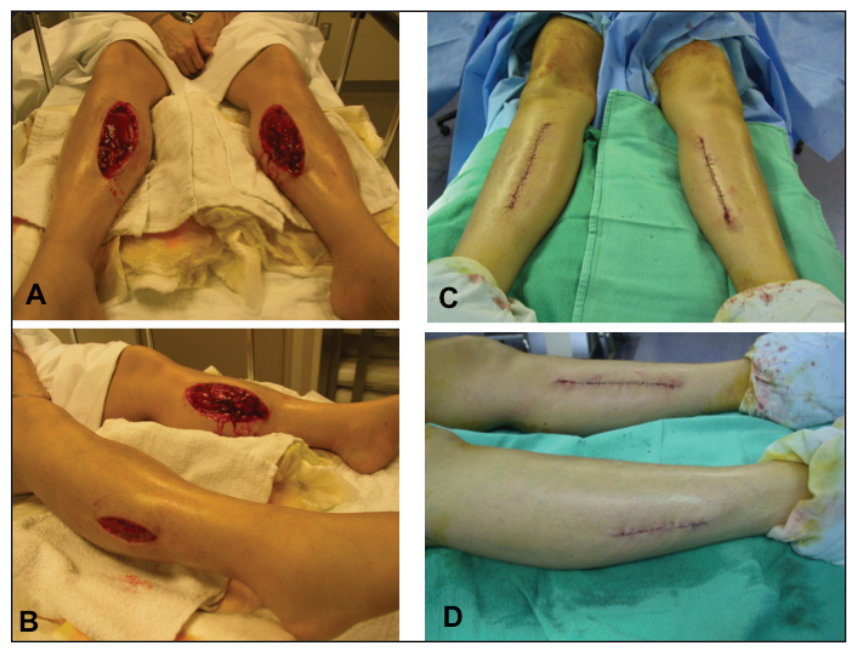

Figure 3) A 47-year-old woman with four fasciotomy leg wounds (A and B) closed using our approach (C and D)

\section{DISCUSSION}

It is well known that the edema from compartment syndrome causes difficulties in the primary closure of fasciotomy wounds. However, current techniques focus on dermal apposition to reduce skin retraction to allow primary closure. None of these techniques address the underlying edema that prevents primary closure. As a result of negligence, the use of these techniques can still cause failures due to the recurrence of compartment syndrome, skin necrosis or wound dehiscence. In two cases referred to us, the referring surgeon attempted to close the fasciotomy wound using the shoelace technique. However, the technique quickly failed because it further precipitated the problem and did not address the underlying edema. Following the initial consultation, we managed the patients using strict elevation and succeeded in closing the wound (Figure 4). We are successful in this approach because our management does not focus on skin retraction. Instead, we regard the edema as our focus of management, which, once alleviated, will lead to a successful primary closure.

Patients who underwent limb elevation were reminded that the success of this approach stringently depended on elevation of the limb. This was reiterated to the patients each day. When compared with the wound closing time in techniques such as the shoelace (mean 8.8 days) (10),

\section{REFERENCES}

1. McKenney M, Nir I, Fee T, Martin L, Lentz K. A simple device for closure of fasciotomy wounds. Am J Surg 1996;172:275-7.

2. Fitzgerald AM, Gaston P, Wilson Y, Quaba A McQueen MM. Long-term sequelae of fasciotomy wounds. Br J Plast Surg 2000;53:690-3.

3. Zannis J, Angobaldo J, Marks M, et al. Comparison of fasciotomy wound closures using traditional dressing changes and the vacuumassisted closure device. Ann Plast Surg 2009;62:407-9.

4. Harris I. Gradual closure of fasciotomy wounds using a vessel loop shoelace. Injury 1993;24:565-6.

5. Singh N, Bluman E, Starnes B, Andersen C. Dynamic wound closure for decompressive leg fasciotomy wounds. Am J Surg 2008;74:217-20.

6. Yang CC, Chang DS, Webb LX. Vacuum-assisted closure for fasciotomy wounds following compartment syndrome of the leg. J Surg Orthop Adv 2006;15:19-23.

7. Saziye K, Mustafa C, Ilker U, Afksendyios K. Comparison of vacuum-assisted closure device and conservative treatment for fasciotomy wound healing in ischaemia-reperfusion syndrome: Preliminary results. Int Wound J 2011;8:229-36.

8. Kakgaia D, Karadimas E, Drosos G, Ververidis A, Trypsiannis G, Verettas D. Wound closure of leg fasciotomy: Comparison of

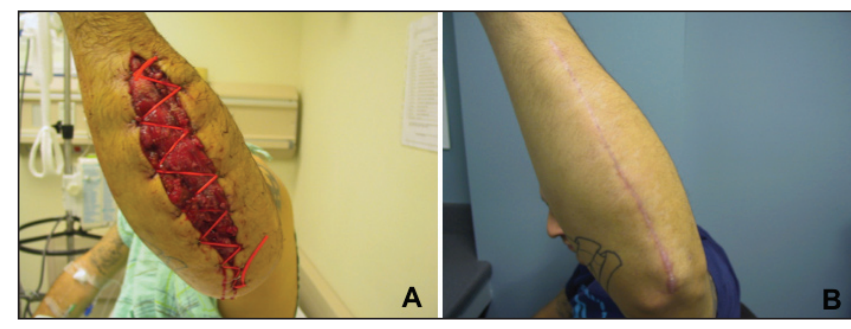

Figure 4) A Failed attempt at fasciotomy wound closure using the shoelace technique. B Wound was successfully closed using our elevation approach

VAC (mean 6.7 days) (6) and subcuticular suture (mean nine days) (8), our approach has the shortest duration (3.4 days). As a result, patients are discharged from the hospital earlier, with fewer costs to both parties. Comparing commercial products, such as the SureClosure, Dynamic Wound Closure, STAR and Silver Bullet Wound Closure devices, our approach does not require the purchase of any expensive devices. This makes elevation an ideal approach for closing fasciotomy wounds in health care settings with minimal resources.

Patients at our institution were given the option to elevate their limb at home if we believed that the patient would comply with our strict elevation guidelines. One patient requested this and the course was uneventful. Originally, we closed fasciotomy wounds using general anesthesia; however, we converted to local anesthesia for six of our former patients, with equal success. Once closed, patients were discharged the following day, although we were confident that patients could be sent home the same day if needed.

\section{CONCLUSION}

Our approach involving strict elevation is a simple and physiologically sound approach that addresses the underlying pathology. We identified the underlying problem in compartment syndrome and we addressed it by applying basic principles. The approach is favourable for its efficient closure time and high success rate, while providing superior cosmetic results. It should be a part of a plastic surgeon's armamentarium in closing fasciotomy wounds, especially in settings with limited resources.

DISCLOSURES: The authors have no financial disclosures or conflicts of interest to declare.

vacuum-assisted closure versus shoelace technique. A randomized study. Injury, February 27, 2012 (Epub ahead of print).

9. Geertruida AM, Govaert G, van Helden S. Ty-Raps in trauma: A novel closing technique of extremity fasciotomy wounds. J Trauma 2010;69:972-5.

10. Zorilla P, Marin A, Gomez LA, Salid JA. Shoelace technique for gradual closure of fasciotomy wounds. J Trauma 2005;59:1515-7.

11. Chiverton N, Redden JF. A new technique for delayed primary closure of fasciotomy wounds. Injury 2000;31:21-4.

12. Taylor RC, Reitsma BJ, Sarazin S, Bell MG. Early results using a dynamic method for delayed primary closure of fasciotomy wounds. J Am Coll Surg 2003;197:872-8.

13. Medina C, Spears J, Mitra A. The use of an innovative device for wound closure after upper extremity fasciotomy. Hand (NY) 2008;3:146-51.

14. Janzing HM, Broos PL. Dermatotraction: An effective technique for the closure of fasciotomy wounds: A preliminary report of fifteen patients. J Orthop Trauma 2004;15:438-41.

15. Tiwari A, Haq AL, Myint F, Hamilton G. Acute compartment syndrome. Br J Surg 2002;89:397-412. 